University of Nebraska - Lincoln

DigitalCommons@University of Nebraska - Lincoln

USDA National Wildlife Research Center - Staff Publications
U.S. Department of Agriculture: Animal and Plant Health Inspection Service

\title{
3-2012
}

\section{HOME RANGES OF THE NILGAI ANTELOPE (BOSELAPHUS TRAGOCAMELUS) IN TEXAS}

Jonathan D. Moczygemba

Texas A\&M University-Kingsville

David G. Hewitt

Texas A\&M University-Kingsville, david.hewitt@tamuk.edu

Tyler A. Campbell

National Wildlife Research Center, tcampbell@eastfoundation.net

J. Alfonso Ortega-S.

Texas A\&M University-Kingsville, alfonso.ortega@tamuk.edu

Justin Feild

King Ranch Incorporated, jfeild@king-ranch.com

See next page for additional authors

Follow this and additional works at: https://digitalcommons.unl.edu/icwdm_usdanwrc

Moczygemba, Jonathan D.; Hewitt, David G.; Campbell, Tyler A.; Alfonso Ortega-S., J.; Feild, Justin; and Hellickson, Mickey W., "HOME RANGES OF THE NILGAI ANTELOPE (BOSELAPHUS TRAGOCAMELUS) IN TEXAS" (2012). USDA National Wildlife Research Center - Staff Publications. 1169.

https://digitalcommons.unl.edu/icwdm_usdanwrc/1169

This Article is brought to you for free and open access by the U.S. Department of Agriculture: Animal and Plant Health Inspection Service at DigitalCommons@University of Nebraska - Lincoln. It has been accepted for inclusion in USDA National Wildlife Research Center - Staff Publications by an authorized administrator of DigitalCommons@University of Nebraska - Lincoln. 


\section{Authors}

Jonathan D. Moczygemba, David G. Hewitt, Tyler A. Campbell, J. Alfonso Ortega-S., Justin Feild, and Mickey W. Hellickson 


\title{
The use of DiazaCon ${ }^{\mathrm{TM}}$ to limit fertility by reducing serum cholesterol in female grey squirrels, Sciurus carolinensis ${ }^{\dagger \ddagger}$
}

\author{
Brenda A Mayle, ${ }^{\text {a* }}$ Mark Ferryman, ${ }^{\text {a }}$ Andrew Peace, ${ }^{\mathrm{b}}$ Christi A Yoder, ${ }^{\mathrm{c}}$ \\ Lowell Miller ${ }^{c}$ and David Cowan ${ }^{d}$
}

\begin{abstract}
BACKGROUND: The grey squirrel, Sciurus carolinensis Gmelin, is an invasive alien species introduced into Great Britain in the late nineteenth century and into Northern Italy during the early twentieth century. Grey squirrels have displaced the native European red squirrel, Sciurus vulgaris L., throughout much of Great Britain and have a significant impact on trees and woodlands through bark-stripping activity. In Britain, eradication is no longer an option at a regional scale, but fertility control offers a non-lethal approach to reducing negative impacts. The cholesterol mimic DiazaCon ${ }^{\mathrm{TM}}$ has been successfully used to inhibit reproduction in some species. These studies aimed to evaluate whether DiazaCon ${ }^{\mathrm{TM}}$ is effective in inhibiting reproduction in grey squirrels.
\end{abstract}

RESULTS: DiazaCon ${ }^{\mathrm{TM}}$ reduced serum cholesterol levels in female grey squirrels at a range of doses. The period of effect increased with increasing dose. Reproduction rate was not significantly different between treatment and control groups owing to a lack of breeding in controls.

CONCLUSIONS: DiazaCon ${ }^{\mathrm{TM}}$ has potential to reduce serum cholesterol levels enough and for a sufficient period to reduce fertility in female grey squirrels. Information on baseline physiology and blood chemistry of grey squirrels is required to inform interpretation of the level of significance of the effect.

C Crown copyright 2012. Reproduced with permission of Her Majesty's Stationery Office. Published by John Wiley \& Sons, Ltd.

Keywords: cholesterol; contraception; DiazaCon ${ }^{\mathrm{TM}} ; 20,25$-diazacholesterol dihydrochloride; fertility control; grey squirrel

\section{INTRODUCTION}

Since its introduction into Britain in the late nineteenth century, the grey squirrel, Sciurus carolinensis Gmelin, has been of increasing concern to woodland and conservation managers owing to both seasonal bark-stripping activity and its impact on woodland biodiversity, particularly on the native red squirrel, Sciurus vulgaris L. Estimates of annual costs to the British timber industry of damage to trees through bark stripping by grey squirrels are $£ 3.40$ [€3.84 by the exchange rate $(£ 1.00=€ 1.13)$ on 11 May 2011] per hectare of vulnerable conifers and $£ 5$ ( $€ 5.65)$ per hectare for the three most vulnerable broadleaf timber tree species: sycamore, Acer pseudoplatanus L., beech, Fagus sylvatica L., and oak, Quercus sp. ${ }^{1}$ As tree damage is believed to be triggered in part by an increase in juveniles in the population during late spring, following breeding in January/February, fertility control offers a potential non-lethal approach to reducing impacts.

In Britain, grey squirrels are generally considered to have two breeding periods in a year. However, the length of the breeding season varies between years and locations, and the timing of the start of the breeding season is primarily influenced by food availability. ${ }^{2}$ The breeding seasons are generally considered to be December/March and late May/July, with peak litter production in March/April and July/August, ${ }^{3}$ although Ferryman et al. ${ }^{4}$ reported evidence of conceptions as early as October and in all months between December and July. The period between conceptions to young becoming independent is $3-4$ months; hence, it is possible for a female squirrel to breed 3 times in a 12 month period, although this has rarely been reported (Forest Research, unpublished). ${ }^{5,6}$ Male squirrels become reproductively active at

\footnotetext{
* Correspondence to: Brenda A Mayle, Forest Research, Centre for Human and Ecological Sciences, Farnham, Surrey GU10 4LH, UK.

E-mail:brenda.mayle@forestry.gsi.gov.uk;ba.mayle@yahoo.co.uk

+ Presented at $8^{\text {th }}$ European Vertebrate Pest Management Conference in Berlin, September $26-30^{\text {th }} 2011$.

‡ This article 'The use of DiazaCon ${ }^{\mathrm{TM}}$ to limit fertility in grey squirrels Sciurus carolinensis (Gmelin)' was written by Brenda Mayle, Mark Ferryman and Andrew Peace of the Forest Research Department. It is published with the permission of the Controller of HMSO and the Queen's Printer for Scotland.

a Forest Research, Centre for Human and Ecological Sciences, Farnham, Surrey, UK

b Forest Research, Centre for Human and Ecological Sciences, Northern Research Station, Roslin, Midlothian, UK

c National Wildlife Research Center, Fort Collins, CO, USA

d The Food and Environment Research Agency, Sand Hutton, York, UK
} 
the beginning of the breeding season and remain so for most of the summer. In the right environmental conditions they are capable of producing high numbers of motile sperm in any month of the year. ${ }^{4}$ Food availability rather than day length is considered to be the key factor in determining seasonality in breeding in grey squirrels. ${ }^{2,3,7,8}$

Population modelling has demonstrated that species with high turnover (high reproduction, high mortality with short generation times) are most sensitive, in terms of speed of population response, to reductions in fecundity rather than increases in mortality rates. ${ }^{9}$ The significance of age at first breeding has also been noted, ${ }^{10}$ with lethal control being suggested as more effective than fertility control for species reproducing at 1 year of age only when adult survival rates exceed 0.56 . Modelling suggests that, if $70 \%$ of a rat population can be sterilised for three generations, the population will be almost eliminated, whereas a similar effort using lethal control would allow the population to rebound to its original size. ${ }^{11}$ For these reasons, fertility control to manage various rodent species is currently under investigation. ${ }^{12,13}$

Cowan and Massei ${ }^{14}$ predicted that imposing $70 \%$ infertility on a population of grey squirrels could drive the population down towards probable extinction after 10 years, and that, even at $50 \%$ infertility, population levels would be significantly reduced to $40 \%$ of the initial population. The response level was similar (55-65\% reduction in population size) and occurred after approximately 5 years, whether the duration of fertility control for individual adult females was 1 year, 3 years or a lifetime. These results suggest that, for the grey squirrel, which has potential for high rates of population increase accompanied with moderate population turnover, a fertility control agent with a single breeding season duration could be useful in managing populations if delivered to a sufficiently high proportion of the breeding female population.

DiazaCon $^{\text {TM }}$ is a cholesterol mimic that inhibits cholesterol production and thereby reduces steroid hormone production and thus can reduce fertility in both males and females. It has been shown to inhibit reproduction in mice, rats and prairie dogs. ${ }^{15-18}$ A reduction in cholesterol of approximately $40 \%$ is needed to reduce reproduction, ${ }^{19}$ and Yoder et al. ${ }^{20}$ showed that DiazaCon ${ }^{\mathrm{TM}}$ treatment over 8 days reduced cholesterol by $>40 \%$ for 2 months in individually caged grey squirrels. As grey squirrels will not breed in cages in captivity, enclosure studies were used to investigate whether DiazaCon ${ }^{\mathrm{TM}}$ would reduce cholesterol levels enough and for a sufficient period to reduce fertility in female grey squirrels.

\section{MATERIALS AND METHODS}

The studies were carried out under a United Kingdom Home Office license (PPL 60/3326) in accordance with the Animals (Scientific Procedures) Act 1986, and all protocols were reviewed and approved by the ethics committees of Forest Research and the Food and Environment Research Agency. DiazaCon ${ }^{\mathrm{TM}}$ was provided by the Avitrol Corporation (Tulsa, OK) via the National Wildlife Research Center (NWRC). Grey squirrels were caught from the wild and individually housed indoors in cages containing a nest box with hessian as bedding material prior to and during the treatment feeding period. The light cycle while squirrels were housed indoors was $12 \mathrm{~h}$ of daylight and $12 \mathrm{~h}$ of darkness, at ambient temperatures. Squirrels were maintained on a diet of equal volumes of peanuts, wholegrain wheat, sunflower seeds and maize throughout, except where otherwise noted, with water freely available.
In studies during 2007 and 2009, female grey squirrels were caught from the wild and held in individual cages to acclimatise for at least 44 days, the gestation period for grey squirrels, before the treatment feeding period. Females were allocated to treatment (16) or control (16) by ranking them by weight and randomly assigning them to treatment groups. Each squirrel was fitted with a pit tag with a unique identifying code (AVID PIc, Lewes, East Sussex, UK) at the base of the tail. One week before the trial started, all females were weighed; a blood sample (for progesterone, cholesterol and desmosterol testing) and a vaginal smear (to check stage of oestrus) were taken. Squirrels were returned to their cage with a clean nest box (to ensure there was no cached food present). Whole wheat was fed for the following 2-3 days, followed by control bait (see below) for the next 3 days prior to the treatment period.

At the end of the 10 day feeding period, all females were returned to the mixed maintenance diet. One week after the last day of treatment, blood samples and vaginal smears were taken from all treatment and from four control females, and they were released into enclosures with reproductively active males. ${ }^{4}$ Control females were allocated to enclosures on the basis of body weight prior to the feeding period, with females of similar body weight allocated to each enclosure where possible. Treatment females were allocated on the basis of mean daily DiazaCon ${ }^{\mathrm{TM}}$ dose intake. Two each of control and treatment females were released with three males into each of two 0.1 ha enclosures ( $A$ and $B$ ); six each of control and treatment females were released with four males into each of two 0.4 ha enclosures ( $C$ and D). All females were marked with Durafur Black R fur dye (ICl Chemical Company) before release to enable behaviour monitoring. Marks were reapplied if necessary when animals were recaptured.

To maximise the likelihood of successful reproduction, males selected for release into the enclosures were scored for reproductive status after Ferryman et al. ${ }^{4}$ Those scoring 7 or more had descended testes, $>51 \mathrm{~mm}$ in length and grey-black in colour, indicating that they were reproductively active and should have high epididymal spermatozoa counts. Males were reassessed at each recapture.

\subsection{7 enclosure study}

Grey squirrels were captured between January 2006 and January 2007 to enable pretreatment sampling in April 2007. Treated bait was fed between 30 April and 10 May inclusive, and females were released into enclosures containing males on 7 and 8 June 2007. As it had only been possible to source 31 suitable adult female grey squirrels by April, the final control female (C16) was caught during June, health checked and marked before release into enclosure C. The trial ended with recapture of all females by 30 September 2007.

The bait for the control and treatment groups was prepared by coating whole wheat ( $1896 \mathrm{~g}$ ) with corn oil $(52 \mathrm{~g})$ and castor sugar $(52 \mathrm{~g})$. DiazaCon ${ }^{\mathrm{TM}}$ at $1.37 \mathrm{mg} \mathrm{g}^{-1}$ was added to treatment bait to achieve a dose of $55 \mathrm{mg} \mathrm{kg}^{-1}$ body weight, assuming $20 \mathrm{~g}$ of treated food was eaten per squirrel each day. The dose was agreed in consultation with the Ethics Review Panel as the optimum dose with respect to putative efficacy and safety.

Up to $40 \mathrm{~g}$ of bait was presented to each squirrel per day at 2 p.m. for 10 days between 30 April and 10 May 2007. Control females (15) received untreated 'control' bait. Treatment females (16) were presented with $20 \mathrm{~g}$ of DiazaCon ${ }^{\mathrm{TM}}$ bait each day, and, if fewer than 10 grains remained at the end of the day or by 9 a.m. the next morning, the remaining treatment and any spilt bait was 
removed and $20 \mathrm{~g}$ of control bait was placed in the cage, to ensure that animals were able to feed ad libitum. For all females, spilt or remaining bait was collected, air dried for $24 \mathrm{~h}$ and weighed to enable daily food intake to be recorded and daily intake of DiazaCon ${ }^{\mathrm{TM}}$ to be calculated. Males were released into enclosures in mid-May just prior to the expected main breeding period, and females were released at the beginning of June. The study ended with recapture of all females between 17 and 25 September 2007.

\subsection{9 enclosure study}

Grey squirrels were captured between September and December 2008 to enable pretreatment sampling in early January 2009. Following the 2007 protocol, treated bait was fed between 12 and 21 January inclusive, and females were released into enclosures containing males on 27 and 28 January. The trial ended with recapture of all females by mid-September 2009.

DiazaCon ${ }^{\text {TM }}$ at $3 \mathrm{mg} \mathrm{g}^{-1}$ was added to treatment bait to achieve a dose of $55 \mathrm{mg} \mathrm{kg}^{-1}$ body weight, assuming $18 \mathrm{~g}$ of treated food was eaten per squirrel each day (based upon the 2007 results). Control animals were presented with $40 \mathrm{~g}$ of control bait each day. Treatment females were presented with $25 \mathrm{~g}$ of treatment bait each day to account for spillage. This was replaced with control bait if fewer than 10 grains remained by the end of the day or the next morning, to ensure that animals were able to feed ad libitum. To minimise the risk of overdose, cumulative food intake was plotted, and, for animals that ate almost all bait, the amount of treatment bait offered was reduced on following days. Two animals barely ate any bait in the first 3 days, so were removed from the trial because, to achieve the target dose, they would have needed to eat a dose close to $90 \mathrm{mg} \mathrm{kg}^{-1}$. Another treatment animal was found in a distressed state and euthanised on day 5 .

\subsubsection{Liver histology}

At the end of the study, samples of liver from four control and eight treatment squirrels (four high-dose, two mid-dose and two low-dose squirrels) were submitted for routine haematoxylin and eosin staining to investigate any effect of DiazaCon ${ }^{\mathrm{TM}}$ on liver function.

\subsection{Behaviour monitoring}

For each study, digital CCTV was used to confirm squirrel presence in the enclosures, to monitor feeding behaviour and interactions between animals and to investigate potential differences between control and treated females. Two feed hoppers were present on each feeding table (one table in each 0.1 ha and two tables in each 0.4 ha enclosure). A camera was trained on the front of each hopper, with the field of view including most of the feeding table and a part of the enclosure beyond.

Squirrel behaviour was categorised into activities performed alone (feeding, grooming, scent marking) and those involving interactions between two or more animals (chasing, group feeding). Feeding periods for females were defined as the time from when the animal first started to forage up to when it stopped feeding, or visibly stopped chewing. Males were only recorded as present and actively feeding. Both male-female and female-female chases were recorded. The duration of a chase was measured from the time when the chaser started to move towards the chased individual to when either one or both animals had left the table or when running ceased.

Additional information on the breeding condition of females, such as the presence of visible nipples or fur missing around nipples, and males with visible testes and scrotal staining ${ }^{4}$ were also noted.

\subsection{Reproductive success}

At each monthly recapture, all squirrels were weighed and the reproductive status of males was scored. ${ }^{4}$ Females were visually assessed for signs of pregnancy (prominent nipples) and lactation (raised, hairless nipples) and weighed, and blood samples and vaginal smears were taken. Early pregnancy is indicated by a metoestrous vaginal smear. ${ }^{21}$

A serum progesterone level of $>10 \mathrm{ng} \mathrm{mL}^{-1}$ is indicative of mid to late ( day 30 ) pregnancy ${ }^{22}$ (Forest Research, unpublished). For each blood sample, $25 \mu \mathrm{L}$ of plasma was analysed for progesterone using IBL Progesterone ELISA kit (RE52231; BioSupply UK Ltd), and OD was read at $450 \pm 10 \mathrm{~nm}$ on a Dynatech MR250 plate reader. This is a solid-phase enzyme-linked immunosorbent assay (ELISA), designed for quantitative determination of progesterone in human serum and plasma. A Forest Research-named veterinarian verified this as suitable for use to test grey squirrel blood plasma. Seven progesterone standards $\left(0-40 \mathrm{ng} \mathrm{mL}^{-1}\right)$ were provided, and the coefficients of variation were given as $5.4-6.99 \%$ for intraassay and $4.34-9.96 \%$ for interassay variation. ${ }^{23}$ ELISA assays were used to identify whether progesterone levels were within specific ranges indicative of pregnancy, rather than to determine absolute values, and were carried out in a temperature-controlled $\left(18-24^{\circ} \mathrm{C}\right)$ environment. Cross-reactivity levels with 11 other steroids were given as 1.1 to $<0.02 \%$. $^{23}$

The remaining blood sample was used to determine plasma cholesterol (non-esterified) and desmosterol concentrations using high-performance liquid chromatography. ${ }^{24}$

Dreys in the enclosures were destroyed to encourage squirrels to use the nest boxes provided. Nest boxes were searched for litters when females showed signs of lactating. However, disturbance was minimised, as females abort or destroy very young juveniles when stressed. At the end of the studies, molecular markers based on nuclear microsatellite regions were used to determine parentage of juveniles present in the nest boxes.

For the 2009 study, all treatment and most control females were euthanised, and placental scars ${ }^{25}$ were assessed as a further indicator of mating success. This information, along with confirmation of lactation and of litter to maternal females through DNA analysis, was used to confirm reproductive success.

\subsection{Data analysis}

Data for each study were analysed separately. Differences in mean food intake between treated and control animals were analysed using ANOVA, with treatment and day and their interaction as factors. Bartlett's test was used to test for the homogeneity of variance. The mean DiazaCon ${ }^{\mathrm{TM}}$ dose was calculated by determining the exact dose for each animal each day, and averaging the daily dose across each treatment group (PROC MEANS; SAS Institute, 2003). Owing to evidence of increasing variance with the mean for cholesterol data, a log transformation was used for analysis of cholesterol response. A mixed model was used, with squirrel as a random effect, to test for differences between control and treated animals over time. Plasma cholesterol and desmosterol concentrations, blood chemistry, body weights and bait consumption among treatment groups were compared using mixed-model analysis (PROC MIXED; SAS Institute, 2003).

For 2007, the CCTV data were evaluated by separating the study period into four intervals encompassing likely periods of 
pregnancy and lactation, and 3 days were randomly selected from each monitoring period, creating 12 sampling days for each of the two enclosures where pregnancy was suspected. Activity was recorded by evaluating $4 \times 10$ min periods each day; two each from the first $4 \mathrm{~h}$ after sunrise and the last $4 \mathrm{~h}$ before sunset. Observations for treatment and control squirrels were analysed separately for the two enclosures. Although some animals were not recaptured at the end of the study, the CCTV footage enabled 'last seen date' and hence total sample days to be confirmed for each animal. The number and length of feeding visits by treated and control squirrels were compared using a Poisson GLM, where 'periods' was the total number of sample days when the squirrel was known to be present. The number of male-female and female-female chases by treated and control squirrels were compared by using a generalised linear mixed model, with animal as a random effect. A similar approach was used for 2009.

\section{RESULTS}

\subsection{7 enclosure study}

\subsubsection{Bait consumption}

Bait intake was not related to body weight. Female control squirrels ate an average of $19.0 \mathrm{~g}$ (SE $1.3 \mathrm{~g}$, range 14.6-29.9 g) of untreated bait per day. As a group, the 15 control squirrels consumed similar quantities of bait during the 10 day feeding period. Slightly less food was eaten on the first day (average of $17.9 \mathrm{~g}$ per squirrel) and most on days 5 and 9 (average of $19.6 \mathrm{~g}$ per squirrel).

Treated female squirrels ate an average of $11.8 \mathrm{~g}$ (SE $0.9 \mathrm{~g}$, range $4.3-19.8 \mathrm{~g}$ ) of bait per day, $9.9 \mathrm{~g}$ of this being DiazaCon ${ }^{\mathrm{TM}}$-treated bait and $2.9 \mathrm{~g}$ of control bait offered as a supplement. There was no obvious aversion to DiazaCon ${ }^{\mathrm{TM}}$ bait from behavioural observations, but vomit was found on the trays of three squirrels on various days of the feeding period. Bait intake figures for those days were subsequently adjusted. All three individuals were recorded as eating normally the following day. Mean daily intake for treatment females was significantly lower in comparison with the control squirrels $\left(F_{1,29}=21.35 ; P<0.001\right)$.

In comparison with the control group, the treated squirrels exhibited a significantly different eating pattern over the 10 day feeding period $\left(F_{9,261}=4.52 ; P<0.001\right)$. Consumption was lowest at the start of the period, $7.1 \mathrm{~g} \mathrm{day}^{-1}$ for the first 2 days, but increased steadily over the period, up to an average of $17.6 \mathrm{~g} \mathrm{day}^{-1}$ for days 9 and 10. DiazaCon ${ }^{\mathrm{TM}}$ bait consumed over days 9 and 10 of the study constituted $66 \%$ of the total food intake.

\subsubsection{DiazaCon ${ }^{\mathrm{TM}}$ dose intake}

As variable quantities of treated bait were consumed per squirrel, predetermined target doses of DiazaCon ${ }^{\mathrm{TM}}$ were not always achieved. The average dose received by treatment females over the 10 days was estimated to be $16.6 \mathrm{mg} \mathrm{kg}^{-1} \mathrm{day}^{-1}$ (range 8.9-25.7 $\mathrm{mg} \mathrm{kg}^{-1} \mathrm{day}^{-1}$ ).

\subsubsection{Cholesterol response}

Across both treatment groups, monthly recapture success was between 73 and $84 \%$, with more treated than control animals caught during each period. Nine treatment and eight control females were caught at every recapture. At the end of the study, 12 of the remaining 14 treatment animals and 12 of the 16 control animals were caught, including two control females that had previously avoided capture. No carcasses were found in any boxes or undergrowth at the end of the study.

Mean pretreatment cholesterol levels for treated $\left(128.3 \mu \mathrm{g} \mathrm{mL}^{-1} ; \mathrm{SE}=12\right)$ and control $\left(137.5 \mu \mathrm{g} \mathrm{mL}^{-1} ; \mathrm{SE}=10.9\right)$ groups did not differ significantly (Fig. 1). Seven days after the final treatment feed, mean plasma cholesterol levels were reduced in both groups but were 39\% lower in treated animals. There was a significant difference (Wald $\left.F_{1,34}=104.9 ; P<0.001\right)$ between the two groups for days 41 to 95 after the last treatment feed, with mean plasma cholesterol for treatment animals reduced to $22 \%$ of control levels by 41 days post-treatment (Fig. 1). Plasma cholesterol in the treatment group remained below $50 \%$ of that of the control group for 68 days after the last DiazaCon ${ }^{\mathrm{TM}}$ feed. By 95 days after the last treatment feed, plasma cholesterol in the treatment group was $66 \%$ of the control group levels, but by final recapture (130 days after the last feed) there was no significant difference between control and treatment groups (Fig. 1). For the control group, plasma cholesterol levels returned to above pretreatment

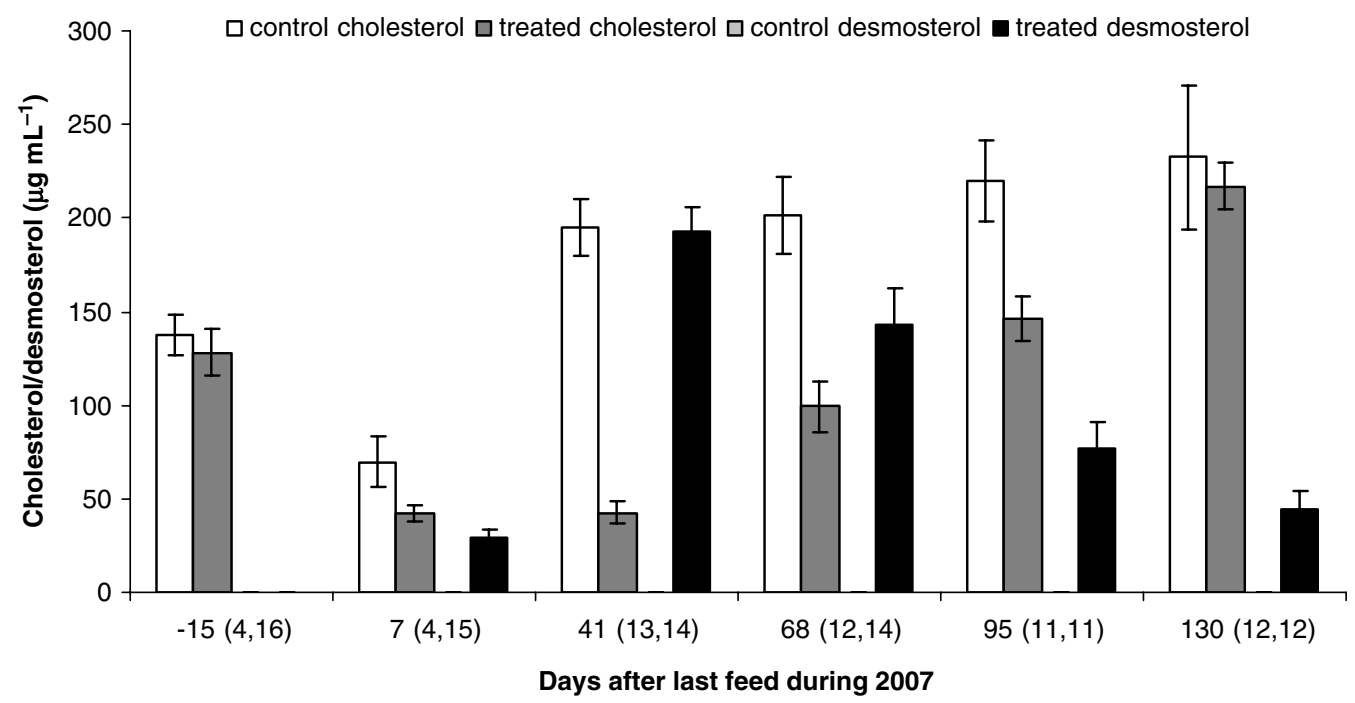

Figure 1. Plasma cholesterol and desmosterol $\left(\mu \mathrm{g} \mathrm{mL}^{-1}\right)$ for treated and control female grey squirrels during 2007 (mean $\pm \mathrm{SE}$ ). DiazaCon ${ }^{\mathrm{TM}}$ bait was fed between 30 April and 10 May. Samples were taken pretrial, post-feeding and at monthly recaptures. The $x$-axis shows days from the last treatment feed and the numbers of animals sampled at each time (control, treatment). 
levels at the first capture and remained at this level until the end of the study. Desmosterol levels reflected the changes in cholesterol levels observed in treated animals.

\subsubsection{Reproductive success}

Metoestrous smears were recorded for three treatment and three control females in June 2007, 41 days after the last treatment feed. There was no evidence of pregnancy in these animals thereafter. Elevated serum progesterone $\left(>10 \mathrm{ng} \mathrm{mL}^{-1}\right)$ was found for another control female around day 68, and pregnancy was confirmed when this female was found with a litter (one male, one female) at day 95. Litter weights indicated that they were born a month earlier, and hence the female must have mated within the first few days of release into the enclosure.

One juvenile male ( $43.9 \mathrm{~g}$ ) was found in another enclosure at day 95, suggesting that it was born earlier that month (August). DNA analysis confirmed a control female, C2, as the mother. Another juvenile male found in the same enclosure in November, after the end of the trial, was confirmed as a sibling through DNA analysis. Two other juveniles found in the same enclosure at day 95 were not related to animals in the enclosure. In conclusion, the only two litters during the 4 month study were born to control females.

\subsubsection{Presence of reproductively active males}

At the beginning of the study period, $71 \%$ of males were reproductively active (score 7 or more) and all enclosures contained a male scoring 8 (92\% probability of high epididymal spermatozoa count). All enclosures had at least one male present scoring 6 or more until day 41 . In enclosure $D$, where the litter was conceived around day 20 , all males scored $>6$, and two males scored 8 . For enclosures where there were no conceptions, one male scored 8 and 9 from day 10 to day 63, and the other two scored 7 from day 11 to day 38 after the last feed. Male scores dropped in two enclosures around day 68 from 4 to 2 (although one male was not caught in each of these enclosures).

\subsection{9 enclosure study}

\subsubsection{Bait consumption}

There was no obvious aversion to bait from behaviour observations, but vomit was found on trays of nine treatment animals on 9 days (between one and five occasions for any animal), and of three control animals on 4 days. Food intake was adjusted to take account of this.

Mean daily bait intake for the control group $(n=16)$ was $21.9 \mathrm{~g}$ (SE $1.3 \mathrm{~g}$, range 11.4-27 g). Average intake for 2009 control squirrels $(21.9 \mathrm{~g}$ ) was not significantly different from the observed 2007 control squirrel consumption ( $\left.19.0 \mathrm{~g} ; t_{29}=1.64 ; P=0.11\right)$. As a group, the 16 control squirrels consumed similar quantities of bait across the whole length of the 10 day feeding period. Average daily consumption ranged from $20.7 \mathrm{~g}$ (day 9) to $23.5 \mathrm{~g}$ (day 7).

As described earlier, three of the 16 treated squirrels did not complete the 10 day feeding period. The remaining 13 treated female squirrels ate an average of $7.2 \mathrm{~g}$ (SE $2.0 \mathrm{~g}$ ) of bait per day, $5.5 \mathrm{~g}$ of this being DiazaCon ${ }^{\mathrm{TM}}$-treated bait and $1.7 \mathrm{~g}$ of control bait offered as a supplement. Individual squirrels varied considerably, two squirrels eating 26.3 and $18.5 \mathrm{~g}$ of food per day and the remaining 11 squirrels between 1.7 and $8.3 \mathrm{~g} \mathrm{day}^{-1}$. Most consumption of the additional control bait was by the two squirrels with the largest food intake. Mean daily intake was significantly lower in comparison with the control squirrels (Mann-Whitney $U=16 ; P<0.001$ ). Although variable on a day to day basis, group food intake showed no overall trend, remaining at similar levels across the 10 days of the baiting period (range $4.3-11.5 \mathrm{~g} \mathrm{day}^{-1}$ ).

\subsubsection{DiazaCon ${ }^{\mathrm{TM}}$ dose intake}

As in 2007, squirrels ate variable quantities of treated bait, and predetermined target doses of DiazaCon ${ }^{\mathrm{TM}}$ were not always achieved, in spite of the concentration in the bait being higher than in 2007. The average dose received by treatment females ( $n=13$ ) over the 10 days was estimated as $28.6 \mathrm{mg} \mathrm{kg}^{-1}$ day $^{-1}$ and varied between 8.8 and $66.2 \mathrm{mg} \mathrm{kg}^{-1}$ day $^{-1}$. Five females received more than the maximum dose achieved in 2007, and the target dose of $55 \mathrm{mg} \mathrm{kg}^{-1}$ day $^{-1}$ was achieved for two females.

\subsubsection{Cholesterol response}

Monthly recapture success was initially $100 \%$ and dropped to $89 \%$ $(25 / 28)$. One treatment female was found dead in a nest box at day 93 after the last treatment feed. At the end of the study, all of the 12 remaining treatment females and 14 of the 16 control females were captured. One control female had avoided capture since day 65 but was caught 12 months later; the remaining control female avoided capture from day 120 but was last seen on CCTV on day 133. No carcasses were found in any boxes or undergrowth at the end of the study.

Control animals $(n=16)$ showed a decline in cholesterol postfeeding and a significant increase in cholesterol on release into the enclosures (Fig. 2), although this was less pronounced than observed in 2007 (Fig. 1). A significant reduction in cholesterol was observed for the treatment group up to 120 days post-treatment, with treatment cholesterol at only $66 \%$ of the control group at this time. Mean desmosterol response reflected the observed decrease in cholesterol.

Dose response was investigated using mixed-model methodology by fitting a cholesterol dose-response curve and modelling time and DiazaCon ${ }^{\mathrm{TM}}$ dosage as regressor variables. Treatment dosage separated readily into five groups: control, $\quad 9.0-15.6 \mathrm{mg} \mathrm{kg}^{-1} \mathrm{day}^{-1}, \quad 18.3-23.3 \mathrm{mg} \mathrm{kg}^{-1} \mathrm{day}^{-1}$, $39.3-43.8 \mathrm{mg} \mathrm{kg}^{-1} \mathrm{day}^{-1}$ and $57.7-66.2 \mathrm{mg} \mathrm{kg}^{-1}$ day $^{-1}$. Cholesterol levels in all treatment dose groups were significantly lower $(P<0.05)$ than in the control group up to day 78 , remaining significantly lower up to day 133 for doses above $39.3 \mathrm{mg} \mathrm{kg}^{-1}$ day $^{-1}$, and for up to 190 days ( 6 months) for the target dose group (57.7-66.2 $\mathrm{mg} \mathrm{kg}^{-1} \mathrm{day}^{-1}$ ).

Although cholesterol levels varied considerably between individuals and recapture dates $\left(92-578 \mu \mathrm{g} \mathrm{mL}^{-1}\right)$, comparison of levels (Mann-Whitney test) between pregnant and non-pregnant females within the control group showed no significant differences in cholesterol or cholesterol index across the eight time periods. This implies that cholesterol levels for all control squirrels were above the threshold level for pregnancy, and there was an 8/14 probability of pregnancy. Pregnancy did not affect cholesterol levels.

Cholesterol levels for treatment females ranged between 15.2 and $411 \mu \mathrm{g} \mathrm{mL}^{-1}$. Treatment females that reproduced conceived from late May to August (120-200 days after the last feed), but their cholesterol levels $\left(89-411 \mu \mathrm{g} \mathrm{mL}^{-1}\right)$ were not significantly different (Mann-Whitney test) to those of treatment females which did not reproduce during this period $\left(53-347 \mu \mathrm{g} \mathrm{mL}^{-1}\right)$ (Table 1). Interpretation of these results is limited by the lack of information on seasonal variation in plasma cholesterol levels of grey squirrels at both population and individual level. 
$\square$ Control cholesterol

Treated cholesterol

Control desmosterol

Treated desmosterol

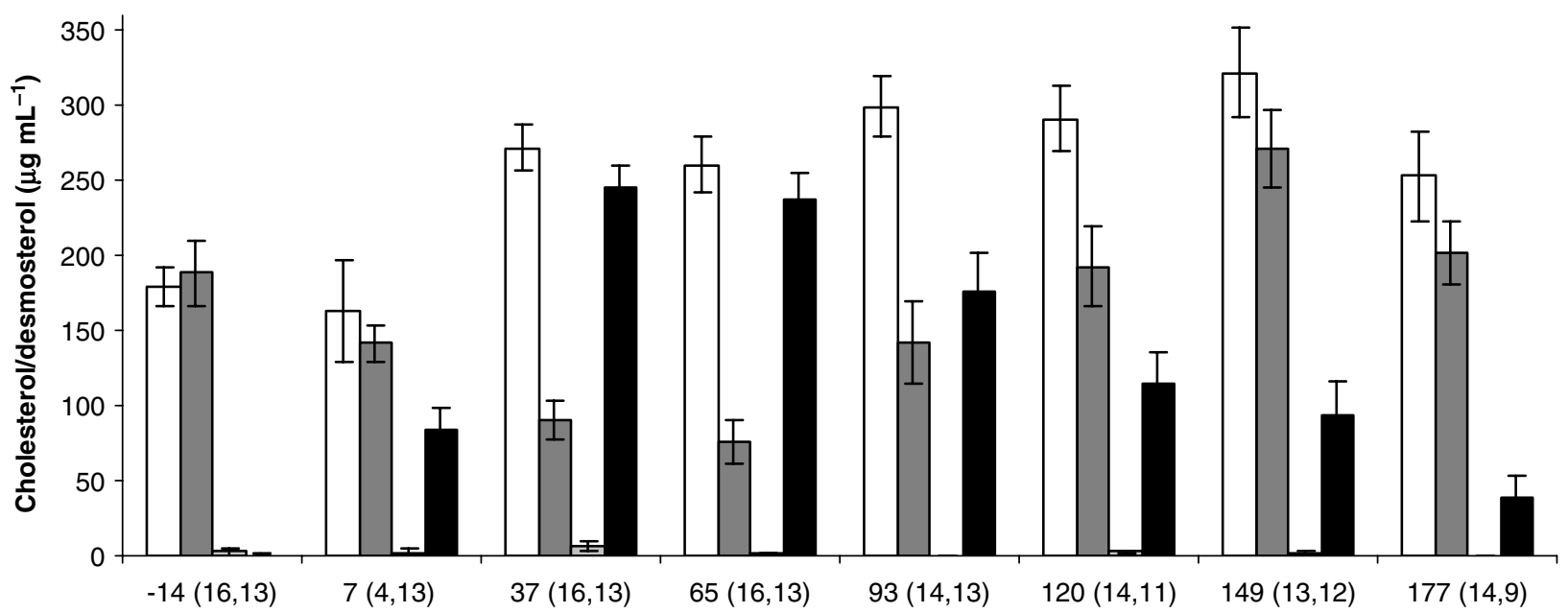

Days after last feed during 2009

Figure 2. Plasma cholesterol and desmosterol $\left(\mu \mathrm{g} \mathrm{mL}^{-1}\right)$ for control and treated female grey squirrels during 2009 (mean $\pm \mathrm{SE}$ ). DiazaCon ${ }^{\mathrm{TM}}$ bait was fed between 12 and 21 January. Samples were taken pretrial, post-feeding and at monthly recaptures. The $x$-axis shows days from the last treatment feed and the numbers of animals sampled at each time (control, treatment).

Table 1. Cholesterol levels $\left(\mu \mathrm{g} \mathrm{mL}^{-1}\right)$ for female grey squirrels fed Diazacon ${ }^{\text {TM }}$ for recapture dates for the second half of the 2009 study (as plasma cholesterols were returning to pretreatment levels)

\begin{tabular}{|c|c|c|c|c|c|c|c|}
\hline \multicolumn{4}{|c|}{ Non-pregnant } & \multicolumn{4}{|c|}{ Pregnant } \\
\hline & Day & Day & Day & & Day & Day & Day \\
\hline Squirrel & 120 & 149 & 177 & Squirrel & 120 & 149 & 177 \\
\hline T2 & 53 & 95 & 130 & T1 & 89 & 201 & 313 \\
\hline T8 & 172 & 224 & 197 & T3 & 113 & 218 & 143 \\
\hline T11 & 311 & 193 & 154 & T4 & 143 & 256 & \\
\hline T14 & 281 & 347 & 239 & T5 & 178 & 297 & \\
\hline T15 & 234 & 339 & 163 & T6 & 242 & 411 & \\
\hline T16 & & 341 & 288 & T7 & 300 & 327 & 190 \\
\hline Average & 210 & 256 & 195 & & 177 & 285 & 215 \\
\hline
\end{tabular}

\subsubsection{Reproductive success}

Although two treatment females showed metoestrus smears (indicative of early pregnancy) at day 65 , this was not followed by elevated progesterone levels or lactation in following months. One of these females was found dead in a nest box at day 93, and there were no placental scars present in the other female at euthanasia.

Metoestrus smears were recorded in two control females at day 149 (Table 2). At the same time, eight control females and six treatment females had slightly increased plasma progesterone levels. Mean plasma cholesterol levels were not significantly different between groups at this time (Fig. 2). Six of these control females and two treatment females went on to show elevated progesterone levels ( $>5 \mathrm{ng} \mathrm{mL}^{-1}$ ) and to have litters, as confirmed through lactation and DNA samples. No litter was found for one control female and for one treatment female that were confirmed to be lactating. Two other control females had elevated progesterone ( $>10 \mathrm{ng} \mathrm{mL}^{-1}$ ) at day 177 , only one of which went on to be confirmed by DNA analysis as having a litter.
Overall, more pregnancies were observed in 2009, nine to control females and five to treatment females. However, only one control female mated soon after release into the enclosures (days 33 to 37), and eight others mated (seven litters found) between days 120 and 160. Two control and one treatment female that had slightly increased serum progesterone $\left(2.5-5 \mathrm{ng} \mathrm{mL}^{-1}\right)$ at day 149 (Table 2) did have placental scars, suggesting that they may have conceived but later reabsorbed embryos. ${ }^{25}$ One treatment female was carrying three large embryos at the end of the study (Table 2).

It was not possible to confirm absolute numbers of juveniles per litter, as females tended to build dreys and were thus not always found with litters in boxes. Disturbance was minimised to prevent females from abandoning juveniles or infanticide. Placental scars were counted to confirm minimum embryo number. Up to 18 juveniles were born to eight control females ( 2.25 per female), and 16 juveniles to five treatment females (3.2 per female) (Table 3). This suggests no subsequent effect of DiazaCon ${ }^{\mathrm{TM}}$ on reproduction.

\subsubsection{Presence of reproductively active males}

In $2009,64 \%$ of males were reproductively active (score 7 or more) on release into the enclosures. All enclosures had at least one male present at all times scoring 6 or more. For the two litters where DNA analysis confirmed parentage, males scored 6 and 7 before and after the conception date. For enclosure $C$, where one litter was conceived between days 33 and 37, after the last feed, one male scored 8 on release into the enclosure on 18 February (day 28). There was, however, no evidence of conceptions or litters born in enclosure $B$, in spite of there being a male scoring 8 and 9 from day 96 to day 160 . The other two males scored 7 from day 120 to day 148 .

\subsection{Post-mortem and liver histology}

Post mortem analysis of the treatment female that had been euthanised during the feeding period in 2009 showed no untoward symptoms related to DiazaCon ${ }^{\mathrm{TM}}$ ingestion. The animal was in fat 


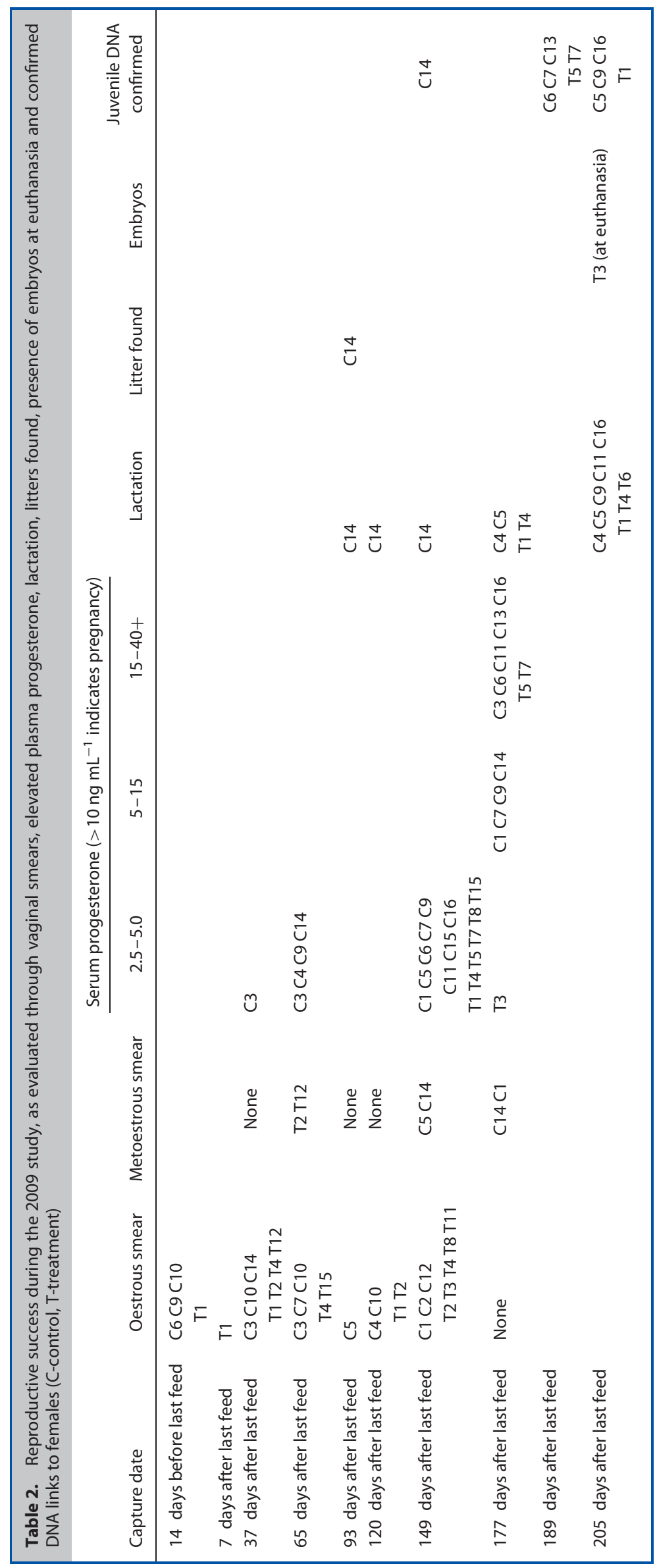


Table 3. Litters confirmed to females in enclosures during 2009. Litter size as confirmed through uterine scars $(u)$ and juveniles counted

\begin{tabular}{|c|c|c|c|c|c|}
\hline & $u$ & Juveniles & Lactation & $\begin{array}{l}\text { DNA confirmed } \\
\text { to female }\end{array}$ & Comments \\
\hline T1 & 3 & 3 & $\mathrm{Y}$ & $\mathrm{Y}$ & \\
\hline T4 & 3 & $?$ & $\mathrm{Y}$ & $\mathrm{N}$ & No litter found \\
\hline T6 & 4 & $?$ & $\mathrm{Y}$ & $\mathrm{N}$ & No litter found \\
\hline T3 & & 3 & & & Embryos at study end \\
\hline T5 & 2 & 3 & & $\mathrm{Y}$ & \\
\hline T7 & 3 & 3 & & Y & \\
\hline T8 & $3 ?$ & $?$ & $\mathrm{~N}$ & & No litter found \\
\hline \multicolumn{6}{|c|}{$\begin{array}{l}\text { Two litters not found; assuming that uterine scars indicate the number } \\
\text { of embryos, then up to } 16 \text { from five female squirrels ( } 3.2 \text { per female) }\end{array}$} \\
\hline C16 & 3 & 3 & Y & $\mathrm{Y}$ & \\
\hline C9 & $?$ & 1 & $\mathrm{Y}$ & $\mathrm{Y}$ & \\
\hline C4 & $?$ & $?$ & $\mathrm{Y}$ & & No litter found \\
\hline $\mathrm{C} 5$ & $?$ & 3 & $\mathrm{Y}$ & $\mathrm{Y}$ & \\
\hline C11 & 4 & $?$ & $\mathrm{Y}$ & & No litter found \\
\hline C14 & 2 & 1 & $\mathrm{Y}$ & $\mathrm{Y}$ & \\
\hline $\mathrm{C} 6$ & 3 & 2 & $\mathrm{~N}$ & $\mathrm{Y}$ & \\
\hline $\mathrm{C7}$ & $?$ & 1 & $\mathrm{~N}$ & $\mathrm{Y}$ & \\
\hline C13 & $?$ & 3 & $\mathrm{~N}$ & $\mathrm{Y}$ & \\
\hline C15 & 1 & 0 & $\mathrm{~N}$ & & $100 \%$ capture \\
\hline $\mathrm{C} 1$ & 3 & 0 & $\mathrm{~N}$ & & $100 \%$ capture \\
\hline \multicolumn{6}{|c|}{$\begin{array}{l}\text { Two litters not found; assuming that uterine scars indicate the number of } \\
\text { embryos, then up to } 18 \text { from eight female squirrels ( } 2.25 \text { per female) }\end{array}$} \\
\hline
\end{tabular}

body condition, but had diffuse hepatic lipidosis (accumulation of fat vacuoles within hepatocytes). This possibly reflected elevated levels of fat turnover, although the animal had eaten similar amounts to other females of similar body weight (3-14.5 g bait day $^{-1}$ ).

Liver samples collected at days 200 to 220 after the last feed showed no obvious histological differences between the two groups and no significant pathological changes. The variation among animals in the amount of intracytoplasmic pigment was within normal limits for the species and may have been age or diet related. The occasional clusters of extramedullary haematopoiesis observed were also considered likely to be within normal limits in a small mammal.

\subsection{Behavioural differences between treated and control groups}

In 2007 it was only possible to investigate differences between treated and control groups rather than pregnant versus nonpregnant. There was no significant difference between treated and control animals in the total number of feeding visits $\left(F_{1,22}=0.00\right.$; $P=0.995)$ or in the average length of visit $\left(F_{1,18}=2.42\right.$; $P=0.137)$. Treated females were chased less by males and chased other females more than would be expected $\left(F_{1,95}=5.35\right.$; $P=0.046$ ). The only control female known to have a litter in enclosure $D$ chased males on three occasions in late June ( $\sim$ days 41 to 50 ) and was chased on three occasions on the same days, by unidentified squirrels.

In 2009, differences between pregnant and non-pregnant females for both control and DiazaCon ${ }^{\mathrm{TM}}$-treated groups were investigated. For females that did not become pregnant and for the prepregnancy period for those that did there was no difference between groups in number of feeding bouts or in length of each feeding bout $(\sim 112.38 \mathrm{~s})$. Pregnant squirrels fed on a similar number of occasions (bouts) but spent slightly longer feeding at each bout (19-26s) than non-pregnant females; this was not significant.

There was no significant difference between treatment groups or pregnant and non-pregnant females in numbers of chases observed in any of the classes: chased by male, chased by treatment, chased by control, chased male, chased treatment, chased control. When behaviour data for non-pregnant squirrels for both studies were combined, there was a marginal increase $(P=0.06)$ in female chases for treated squirrels.

\section{DISCUSSION}

These studies were successful in demonstrating an effect of DiazaCon $^{\mathrm{TM}}$ on plasma cholesterol levels in grey squirrels in a natural environment and in determining the dose required to maintain plasma cholesterol levels significantly lower than those of control females for up to 6 months, following a 10 day feeding period. Whether it would be possible to achieve the required daily bait intake levels in a field situation, in the presence of natural food supplies, is yet to be ascertained.

The authors were confident that no squirrels escaped from the enclosures, although new squirrels did enter from outside, mainly males, possibly attracted by oestrous females which are known to vocalise in order to advertise their reproductive status. ${ }^{26}$ All immigrant squirrels were removed as soon as they were found, to minimise any social disruption within the enclosures.

\subsection{Bait and dose intake}

A greater range of dose intake was achieved in 2009 than in 2007, in spite of the lower bait intake overall $\left(7.2 \mathrm{~g}\right.$ day $^{-1}$ versus $11.8 \mathrm{~g} \mathrm{day}^{-1}$ ) and lower DiazaCon ${ }^{\mathrm{TM}}$ bait intake ( $5.5 \mathrm{~g} \mathrm{day}^{-1}$ versus $\left.9.9 \mathrm{~g} \mathrm{day}^{-1}\right)$. This suggests that the target dose can be achieved with a concentration of $3 \mathrm{mg} \mathrm{g}^{-1}$ DiazaCon $^{\mathrm{TM}}$ in the bait.

Although vomit was found on the trays of treatment animals in both studies, and for a few control animals in 2009, previous studies have shown that wholegrain wheat is readily accepted and eaten by grey squirrels (Forest Research, unpublished). It was chosen as the most suitable bait for presenting warfarin poison to squirrels in Great Britain, as it is not cached and the wholegrain is eaten, hence minimising non-target risks. ${ }^{27}$ DiazaCon $^{\text {TM }}$ has a bitter taste; this may explain why more squirrels had vomit on their trays in 2009 than in 2007. However, this did not appear to prevent animals from feeding on the bait on subsequent days, and bait enhancers might help to minimise this in field application.

\subsection{Cholesterol response}

These studies demonstrate that DiazaCon ${ }^{\mathrm{TM}}$ fed over a 10 day period at doses up to $66.21 \mathrm{mg} \mathrm{kg}^{-1}$ day $^{-1}$ is effective at reducing cholesterol levels by more than $40 \%$ in female grey squirrels for up to 4 months. Although a higher dose might be expected to lead to a later conception date, there was no relationship between conception date in 2009 and dose of DiazaCon ${ }^{\mathrm{TM}}$. The treatment female receiving the highest dose conceived earliest in that group, around day 130 .

Although the range of plasma cholesterol values observed (9.2-57.8 $\left.\mathrm{mg} 100 \mathrm{~mL}^{-1}\right)$ was wider than that reported by Yoder et al. ${ }^{20}\left(2.6-18.1 \mathrm{mg} 100 \mathrm{~mL}^{-1}\right)$, they are of a similar order to those reported by Guthrie et al. ${ }^{28}\left(68.8-185.4 \mathrm{mg}^{\left.100 \mathrm{~mL}^{-1}\right)}\right.$ who 
found no significant effect of sex or treatment (shot versus cage trapped and held for up to $24 \mathrm{~h}$ ) for grey squirrels taken between September 1964 and February 1965. As might be expected, the plasma non-esterified cholesterol levels observed were lower than the serum total cholesterol levels reported by Hoff et al. ${ }^{29}$ (124-448 mg $100 \mathrm{~mL}^{-1}$ ), who sampled animals trapped in the wild and euthanised rather than regularly sampling animals held in captivity over a period of time.

Cholesterol levels of control females in both studies increased significantly once they were released into the enclosures and remained so for at least 4 months. Interpretation of the results is limited by lack of information on seasonal variation in plasma cholesterol levels for grey squirrels, held in cages or enclosures, at the individual or population level.

\subsection{Effect of DiazaCon ${ }^{\mathrm{TM}}$ on reproduction}

These studies aimed to have treated female grey squirrels in the enclosures with reproductively active males for the periods when most conceptions would be expected to take place (April to August), based upon the literature and previous unpublished studies. $^{30}$ In Britain, Webley and Johnson ${ }^{21}$ found that $30 \%$ of female grey squirrels have two litters, with peak litter production in March/April and June/July, but Gurnell ${ }^{2,31}$ suggests that peak litter production is in July/August. Ferryman et al. ${ }^{4}$ also found that peak matings in their study occurred in April and June in 2002 and in May and June in 2003.

It was not possible to demonstrate a significant effect on reproduction on account of the fact that so few control females bred during the critical early phase of release into the enclosures, in spite of the fact that reproductively active males were present, and oestrous smears were found before feeding in $12-22 \%$ of captive females (7/32 in 2007 and 4/32 in 2009). Webley and Johnson $^{21}$ suggest that the female grey squirrel is an induced ovulator, requiring the presence of a male and adequate space for the induction of oestrus. They also state that captive female squirrels do not show regular oestrous cycles, and metoestrous smears are indicative of early pregnancy.

In both studies, oestrous smears were found in recaptured females 1 month after release into enclosures (7/27 in 2007 and $7 / 32$ in 2009), and metoestrous smears were found in a further three control females and three treatment females in 2007 , suggesting that mating had taken place. The suitability of the enclosures for breeding was further confirmed by a mating recorded on 12 June 2007 on CCTV within 6 days of release into the enclosures. At least one control female in each study mated soon after release into the enclosures. During the 2007 study, only control females produced litters $(n=2)$, and in 2009 most females mated after cholesterol levels in treated females had returned to pretreatment levels.

Densities of seven squirrels in the 0.1 ha enclosures and 16 squirrels in the 0.4 ha enclosures were chosen, as successful breeding had previously been recorded at these densities (although not all females bred in all seasons in each year). Although a higher density than that reported from the United States for successful breeding of grey squirrels (10-12 in a 0.85 ha enclosure), ${ }^{21}$ it is less than that reported for successful breeding in Britain (7-8 squirrels in a 0.07 ha enclosure). ${ }^{21}$ Webley $^{32}$ did, however, suggest that, at densities of 20 squirrels ha ${ }^{-1}$, mating appeared to be normal, but litters of subordinate females did not survive. It is possible that successful earlier mating did take place in the enclosures, but that litters did not survive to be found.
Furthermore, in 2007, treated females were chased less by males than were control females, and, by inference, were thus less attractive to males. This provides indirect behavioural evidence of a possible effect of DiazaCon ${ }^{\mathrm{TM}}$ on fertility. The slight increase in time spent feeding by pregnant females would be expected for animals preparing for birth and lactation.

Previous studies suggest that food availability is more important than day length in regulating reproductive development and determining timing and success of breeding. 2,3,7,8 The present authors ensured that supplementary food and water was available ad libitum in the enclosures, as well as natural food available as buds, leaves, fruits and seeds of the enclosure trees and shrub/ground vegetation, invertebrates, etc.

\subsubsection{Presence of reproductively active males}

It is unlikely that the lack of the presence of reproductively active males was the reason for the observed lack in successful breeding in the control groups during the early phase of each study. The authors ensured that each enclosure had at least one reproductively active male present, scoring $\geq 6$, when females were released. The fact that reproductively active immigrant males, scoring 7 and 8 , were caught during both studies (one each in enclosures $B$ and $C$ in 2007 and two each in enclosures $A$ and $B$ in 2009) suggests that females may have been actively advertising their receptivity to males through vocalisations or other means. ${ }^{26}$ Although males exhibit regression of testicular development, this is not in synchrony within a population, so that at no time are all males regressed. ${ }^{33}$ Ensuring ad libitum food supply should also have ensured that males remained reproductively active, as there is evidence that male reproductive development is more likely to be driven by availability of food than by day length. $3,8,21$

\subsubsection{Effect on litter size}

Although a separate nest box was available for each adult present in the enclosures, squirrels built substantial dreys within 2 days. In the wild, squirrels will use more than one and share dreys, and females will actively move young between dreys. To encourage females to use boxes, dreys were poked out as soon as they were seen. In 2007 the authors were confident that no other litters were born, as no other females lactated. In 2009, evaluation of placental scars enabled confirmation of litter size (Table 3). There was no indication of a subsequent effect of DiazaCon ${ }^{\mathrm{TM}}$ on litter size once cholesterol levels in treated females had returned to normal.

\subsection{Side effects of DiazaCon ${ }^{\mathrm{TM}}$ treatment $^{\mathrm{T}}$}

There was no evidence of any negative effect of treatment in grey squirrels either for the animal that was euthanised or from the liver samples. Although there was some hepatic lipidosis observed in one treatment female, the animal was in fat body condition and daily food intake was similar to other females of similar body weight (3-14.5 $\mathrm{g}$ bait day $\left.{ }^{-1}\right)$, suggesting that elevated levels of fat turnover for this animal were unlikely.

\section{CONCLUSIONS AND THE FUTURE}

The study protocol was influenced by the lack of suitable quantitative bait makers for grey squirrels (Forest Research, unpublished), necessitating individual caging and feeding of squirrels to monitor daily bait and dose intake. Feeding behaviour at hoppers was investigated as an alternative approach to monitoring bait intake (Forest Research, unpublished), but high 
intra- and interanimal variation confirmed this as unsuitable for monitoring bait intake in an enclosure situation.

For future reproduction inhibition studies in grey squirrels, an alternative approach would be to monitor established groups of males and females in the enclosures for successful breeding over at least a 12 month period. The target agent could then be fed to animals in a subset of the enclosures and evaluated against the previous year's reproductive output. Although it would be possible to estimate mean daily bait intake for the group of animals in each enclosure, it would not be possible to establish daily dose intake for individual animals, unless a suitable quantitative bait marker became available for grey squirrels. All animals in one enclosure would either be in the control or in the treatment group. This approach would have significant cost implications.

The ideal agent for practical field use to manage grey squirrel populations should be species specific in mode of action (or delivery), effective for a number of years, or at least a full breeding season following treatment, and be delivered through treated bait that is readily eaten by squirrels and not cached. The duration of reduced plasma cholesterol induced by DiazaCon ${ }^{\mathrm{TM}}$ is not long term. However, these studies demonstrate that grey squirrels will take wholewheat bait treated with DiazaCon ${ }^{\mathrm{TM}}$ at levels that create a significant reduction in blood cholesterol that might be expected to impair fertility. Also, for animals receiving the target dose of $55 \mathrm{mg} \mathrm{kg}^{-1}$, plasma cholesterol is significantly reduced for up to 6 months, which might be sufficient to reduce fertility for a single breeding season or at least delay reproduction to a less favourable time of year in terms of juvenile survival. Although it was not possible to demonstrate a significant effect of DiazaCon ${ }^{\mathrm{TM}}$ on reproduction of grey squirrels, no detrimental effects on squirrel behaviour or physiology at these doses were observed.

It is unlikely that DiazaCon ${ }^{\mathrm{TM}}$ will become available in the short term for field use to manage grey squirrels in Britain. Although other agents such as GonaCon ${ }^{\mathrm{TM}}$ (a GnRH immunocontraceptive vaccine) have been developed to have a long-term effect with a single injection, the development of oral delivery for such vaccines remains a difficult technology and is not expected to be developed soon. ${ }^{10}$

These studies demonstrate that for many problem wildlife species there is a lack of baseline physiological information, individual animal variation and the factors driving these. This information gap needs to be addressed before studying the effect of any control agent designed to disrupt processes such as reproduction.

\section{ACKNOWLEDGEMENTS}

The authors thank the referees for comments on earlier drafts, and Joan Cottrell and Stuart A'Hara for microsatellite analysis of tissue samples. The work was funded by the Forestry Commission Great Britain, Defra and USDA.

\section{REFERENCES}

1 Williams F, Eschen R, Harris A, Djeddour D, Pratt C, Shaw RS, et al, The economic cost of invasive non-native species on Great Britain. $C A B$ Project No. VM10066, CABI Europe - UK (2010).

2 Gurnell J, Squirrel numbers and the abundance of tree seeds. Mammal Rev 13:133-148 (1983)

3 Dubock AC, Male grey squirrel (Sciurus carolinensis) reproductive cycles in Britain. J Zool Lond 188:41 - 51 (1979).

4 Ferryman M, Mayle BA and Morgan GW, Visual method for evaluating the state of sexual development in male grey squirrels (Sciurus carolinensis). Reprod Fertil Dev 18:383-393 (2006).
5 Middleton AD, The Grey Squirrel. Sidgwick \& Jackson Ltd, London, UK (1931).

6 Shorten M, Squirrels. Collins, London, UK (1954).

7 Smith NB and Barkalow FS, Precocious breeding in the gray squirrel. $J$ Mammal 48:328-330 (1967).

8 Tait AJ and Johnson E, Spermatogenesis in the grey squirrel (Sciurus carolinensis) and changes during sexual regression. J Reprod Fert 65:53-58 (1982).

9 Krebs CJ, Current paradigms of rodent population dynamics - what are we missing?, in Ecologically-based Management of Rodent Pests, ed. by Singleton GR, Hinds LA, Leirs H and Zhang Z. [Online]. Australian Centre for International Agricultural Research, Canberra, Australia, pp. 33-48 (1999). Available: http://aciar.gov.au/files/node/323/ecologically_based_rodent_ management_part_1_19909.pdf Accessed [20 February 2012].

10 Fagerstone KA, Miller LA, Killian G and Yoder CA, Review of issues concerning the use of reproductive inhibitors, with particular emphasis on resolving human-wildlife conflicts in North America. USDA National Wildlife Research Centre Staff Publication, paper 992 (2010).

11 Knipling EF and McGuire JU, Potential role of sterilization for suppressing rat populations, a theoretical appraisal. Technical Bulletin No. 1455, Agricultural Research Service, United States Department of Agriculture, Washington, DC (1972).

12 Jacob J, Singleton GR and Hinds LA, Fertility control of rodent pests. Wildl Res 35:487-493 (2008).

13 Singla $\mathrm{N}$ and Meenu $\mathrm{M}$, Reproductive inhibition with gossypol in the lesser bandicoot rat, Bandicota bengalensis, in Abstracts of 8th European Vertebrate Pest Management Conference, Berlin, Germany, 20-30 September 2011, ed. by Jens J and Esther A (2011).

14 Cowan DP and Massei G, Wildlife contraception, individuals, and populations: how much fertility control is enough?, in Proceedings of 23rd Vertebrate Pest Conference, ed. by Timm RM and Madon MB. University of California, Davis, CA, pp. 220-228 (2008).

15 Hikim AP, Effect of 22,25-diazacholesterol dihydrochloride on the spermatogenesis of a wild rat Bandicota bengalensis. Int J Fert 32:320-323 (1987).

16 Hikim AP and Chakraborty J, Effects of diazacholesterol dihydrochloride (SC-12937), an avian antifertility agent, on rat testis. J Androl 7:277-284 (1986).

17 Nash P, Furcolow CA, Bynum KS, Yoder CA, Miller LA and Johnstone JJ, 20,25-Diazacholesterol dihydrochloride as an oral contraceptive for black-tailed prairie dog population management. Hum-Wildl Conflicts 1:60-67 (2007).

18 Singh SK and Chakravarty S, Antispermatogenic and antifertility effects of 20,25-diazacholesterol dihydrochloride in mice. Reproductive Toxicol 17:37-44 (2003).

19 Yoder CA, Bynum KS and Miller LA, Development of DiazaCon ${ }^{\mathrm{TM}}$ as an avian contraceptive, in Proceedings of the Wildlife Damage Management Conference 11, ed. by Nolte DL and Fagerstone KA. National Wildlife Research Center, Fort Collins, CO, pp. 190-201 (2005).

20 Yoder CA, Mayle BA, Cowan DP and Fagerstone KA, Feeding of grey squirrels (Sciurus carolinensis) with the contraceptive agent DiazaCon $^{\mathrm{TM}}$ : effect on cholesterol, hematology, and blood chemistry. Integrative Zool 6:409-419 (2011).

21 Webley GE and Johnson E, Reproductive physiology of the grey squirrel (Sciurus carolinensis). Mammal Rev 13:149-154 (1983).

22 Tait AJ, Pope GS and Johnson E, Progesterone concentrations in peripheral plasma of non-pregnant and pregnant grey squirrels (Sciurus carolinensis). J Endocr 89:107-116 (1981).

23 IBL Progesterone ELISA (RE52231) Instructions for Use. IBL Immuno Biological Laboratories (2005).

24 Johnston JJ, Goodall MJ, Yoder CA, Furcolow CA, Goldade DA, Kimball BA, et al, Desmosterol: a biomarker for the efficient development of 20,25-diazacholesterol as a contraceptive for pest wildlife. J Agric Fd Chem 51:140-145 (2003).

25 Mowat G, Boutin S and Slough B, Using placental scar counts to estimate litter size and pregnancy rate in Lynx. J Wildl Manag 60:430-440 (1996).

26 Koprowski JL, Do oestrus female gray squirrels, Sciurus carolinensis, advertise their receptivity? Can Field Nat 106:392-394 (1992).

27 Taylor JC, Lloyd HG and Shillito JF, Experiments with warfarin for grey squirrel control. Ann Appl Biol 61:303-349 (1968). 
28 Guthrie DR, Osborne JC and Mosby HS, Physiological changes associated with shock in confined gray squirrels. J Wildl Manag 31:102-108 (1967).

29 Hoff GL, McEldowny LE, Bigler WJ, Kuhns LJ and Tomas JA, Blood and urinary values in the gray squirrel. J Wildl Dis 12:349-352 (1976).

30 Forestry Commission (2002). [Online]. Available: http://www. forestry.gov.uk/newsrele.nsf/WebPressReleases/8EE462F6AE8 228FA80256C13003C7CCD Accessed [30 August 2011].
31 Gurnell J, The Natural History of Squirrels. Christopher Helm, London, UK (1987).

32 Webley GE, A study of aspects of the reproductive physiology in the male and female grey squirrel (Sciurus carolinensis). PhD Thesis, University of Reading, Reading, Berks, UK (1982).

33 Pudney J, Seasonal changes in the testis and epididymis of the American grey squirrel Sciurus carolinensis. J Zool 179:107-120 (1976). 